\title{
Effect of pellet size and additive on silica carbothermic reduction in microwave furnace for solar grade silicon
}

\author{
Fillali Cherif ${ }^{1,2, *}$, Ilyes Baba Ahmed ${ }^{3}$, Abdelkader Abderrahmane $^{2,4}$, \\ SAAD HAMZAOUI ${ }^{1,2}$ \\ ${ }^{1}$ Département de Technologie des Matériaux, Faculté de physique, Université des Sciences et Ode la Technologie d'Oran \\ Mohamed Boudiaf, BP 1505 Oran (31000), Algérie \\ ${ }^{2}$ Laboratoire de Microscopie Electronique et Sciences des Matériaux, Université des Sciences et de la Technologie d'Oran \\ Mohamed Boudiaf, BP 1505 Oran (31000), Algérie \\ ${ }^{3}$ Département de Physique, Faculté Des Sciences, Université Saad Dahlab Blida1, BP 270 Blida (09000), Algérie \\ ${ }^{4}$ Division Microélectronique et Nanotechnologie, Centre de Développement des Technologies Avancées, Cité 20 août 1956 \\ Baba Hassen, Alger (16000), Algérie
}

\begin{abstract}
Silicon as a raw material for solar cells can be produced by numerous methods. The carbothermic reduction of silica using electric arc furnace is the most widely used process in silicon industry. This paper presents a new approach to produce solar grade silicon using microwave furnace. Pellets of different sizes were prepared from a mixture of silica and carbon using water and polyvinyl alcohol as binder agents. Raman spectra indicated a peak at about $515 \mathrm{~cm}^{-1}$ attributed to silicon in the pellets prepared with polyvinyl alcohol, and peaks at about $523 \mathrm{~cm}^{-1}$ and $794 \mathrm{~cm}^{-1}$ attributed to silicon and silicon carbide, in the pellets prepared with water. The pellet size affects the absorption of microwave energy emitted from the magnetrons. Polyvinyl alcohol as a binder agent is promising for the production of silicon using microwave furnace.
\end{abstract}

Keywords: microwave furnace; carbon; silica; solar grade silicon; solar cells

\section{Introduction}

For more than 100 years, the process of silicon production has been in continuous development for application in electronic chips and solar panels. Several research projects have been conducted to produce low cost silicon for the photovoltaic industry [1].

Carbothermic reduction is a common industrial procedure to manufacture solar grade silicon from silicon dioxide $\left(\mathrm{SiO}_{2}\right)$ in an electric arc furnace according to the simplified reaction equation:

$$
\mathrm{SiO}_{2}+2 \mathrm{C} \longrightarrow \mathrm{Si}+2 \mathrm{CO}
$$

The reaction in equation 1 seems to be the overall reaction for silicon production. Moreover, many chemical reactions with different stoichiometry are possible in the reaction system between silica and carbon (-) as shown in Table 1.

\footnotetext{
*E-mail: fillali.cherif@univ-usto.dz
}

Nevertheless, the reaction mechanisms are still being researched and developed in order to find new processes, which require the knowledge of how to control this complex reaction system between solid, liquid and gaseous matter, as illustrated in Table 1, and to increase the energy efficiency process during silicon production. Heating a mixture of silica and carbon (mole ratio 1:2) produced silicon carbide $(\mathrm{SiC})$ and silicon monoxide ( $\mathrm{SiO})$ but not silicon [2].

Therefore, the reduction of $\mathrm{SiO}_{2}$ with $\mathrm{C}$, at high temperature, may form silicon monoxide $(\mathrm{SiO})$, carbon monoxide (CO) and silicon carbide ( $\mathrm{SiC})$ as shown in Table 1 . Where, $\mathrm{g}, 1$ and s correspond to gas, liquid, and solid phases, respectively. As the reaction in equation 2, equation 3 and equation 5 can be controlled by the amount of silicon monoxide, so it is assumed that $\mathrm{SiO}$ is the most important reactant by-product in silicon production. Moreover, the analyses of gas phases using Q-mass spectrometer cannot detect $\mathrm{SiO}$ gas but only $\mathrm{CO}$ 
Table 1. Possible reactions between $\mathrm{SiO}_{2}-\mathrm{C}$ during heating process.

$$
\begin{array}{r}
\text { Reaction equation } \\
\mathrm{SiO}_{2}+2 \mathrm{C} \rightarrow \mathrm{Si}+2 \mathrm{CO} \\
\mathrm{SiO}_{2}(s)+\mathrm{C}(s) \rightarrow \mathrm{SiO}(g)+\mathrm{CO}(g) \\
\mathrm{SiO}(g)+2 \mathrm{C}(s) \rightarrow \mathrm{SiC}(s)+\mathrm{CO}(g) \\
2 \mathrm{SiO}_{2}(s)+\mathrm{SiC}(s) \rightarrow 3 \mathrm{SiO}(g)+\mathrm{CO}(g) \\
\mathrm{SiO}(g)+\mathrm{SiC}(s) \rightarrow 2 \mathrm{Si}(s)+\mathrm{CO}(g) \\
\mathrm{SiO}_{2}(l)+\mathrm{Si}(l) \rightarrow \mathrm{SiO}(g)
\end{array}
$$

gas. In addition, a new method was used for weight loss of $\mathrm{SiO}$ and $\mathrm{CO}$ gases [3]. As the chemical reaction in equation 4 shows, the silicon carbide can enhance the silicon production yield [1], and it can prevent the loss of $\mathrm{SiO}$ gas as shown in the reaction equation 5 . In turn, silicon monoxide $(\mathrm{SiO})$ is an important element to increase the amount of silicon.

The chemical reactions that occur during the carbothermic reduction of silica depend not only on the raw material properties but also on different heating sources and their interactions with the materials [4]. In this paper, we developed an approach for solar grade silicon production using microwaves as a heating source. Amorphous carbon such as activated carbon, coke, charcoal, and coal represent good microwave absorbers. Thus, we used carbon for heating and reaction in the microwave processes. The main advantages of this process are safety, ease to manipulate, and fast heating. The results of the analysis show the advantages for silicon production.

The following part of the paper is organized as follows: Section 2 describes an experimental study that we conducted during our research. In Section 3, we discuss our results and, finally, Section 4 summarises the results of this work and draws conclusions.

\subsection{Microwave heating theory}

The idea of microwave heating is to dissipate the energy of microwave by converting it into heat, depending on the properties of a material and its ability to absorb microwave energy [5].
Materials are classified into three different groups when exposed to microwave irradiation: microwave absorbers (silicon carbide, charcoal and activated carbon), microwave transparent (alumina, quartz), and microwave reflectors (solid metals) [6].

The properties of materials and their ability to absorb the power of microwaves depend on how they store the energy, which is connected with a dielectric constant and how they dissipate energy which is connected with dielectric loss. The ratio of these two factors is defined by the loss tangent tan and the relative permittivity [7] according to the following equation:

$$
\tan \delta=\frac{\varepsilon_{r}^{\prime \prime}}{\varepsilon_{r}^{\prime}}
$$

In general, frequency dependence of dielectric constant and dielectric loss in some materials is strongly influenced by temperature [8]. Knowing the properties of a material allows us to predict its ability to absorb the energy supplied by magnetrons. The average power absorbed by a certain amount of material when heated dielectrically is expressed as [9]:

$$
P=2 \pi f \varepsilon_{0} \cdot \varepsilon_{r} \tan (\delta) E^{2}
$$

where is the dissipated power [W/ $\left./ \mathrm{cm}^{3}\right]$, the energy source is represented by the electrical field strength $[\mathrm{V} / \mathrm{cm}]$ and is frequency $[\mathrm{Hz}]$; the dielectric constant and the loss tangent are the material properties. Generally, for industrial microwave furnaces, the frequency fis equal to $2.45 \mathrm{GHz}$ [10].

When a microwave radiation penetrates a material, such as a dielectric, an energy loss occurs, because the thermal conductivity of the material depends on the absorption and penetration depth of microwave energy, and then, as thermal conductivity increases, heat dissipation also increases [11]. To determine the uniformity of heating and the depth of the microwaves penetration into a material, it is important to know the dielectric properties of the material $[9,12]$. The penetration depth of microwave energy from the surface to the bulk of material is defined as the depth at which the power decreases by half its value $[9,13,14]$ In this work, 
the results show that the penetration depth is influenced by the pellet size, homogeneity of powder mixture and the additive of polymer.

\section{Experimental study}

\subsection{Heating mechanism}

Microwave heating systems in the industrial sector differ from each other depending on their applications. As shown in Fig. 1, the microwave system used in this study includes microwave power supply, magnetron head, cooling system, and waveguide components (isolators/circulators, tuning system and waveguides).

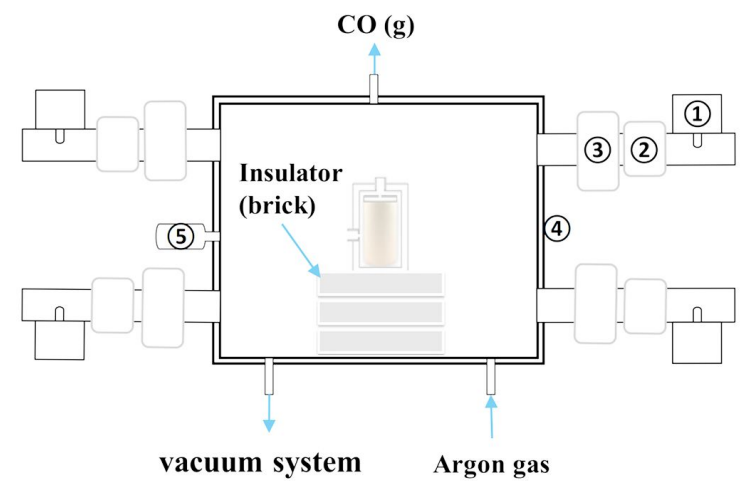

Fig. 1. Schematic illustration of multi-mode microwave heating system.

The sample is heated in a multi-mode microwave furnace by four magnetrons (1), each having a variable microwave power with a maximum value of $3 \mathrm{~kW}$ at a frequency of $2.45 \mathrm{GHz}$. The tuning system (3) is used to reflect unabsorbed microwaves into the furnace chamber (4) and increase energy efficiency. Moreover, circulators (2) are used to protect the magnetron from reflected microwave energy by a three-port device system using ferrite technology (magnets), typically circulators combined with a water load, which has a high power absorption capacity. The temperature is measured by infrared thermometers (5). The experiments were carried out according to the heating profile after removing all the air from the chamber using a rotary pump to avoid oxygen oxidation and injecting of an inert gas such as argon (Ar).

\subsection{Sample}

The study aims to investigate the effect of pellet size on the carbothermic reduction of silica sand by microwave irradiation. We have used 3 moles of powdered crystalline silica $\left(\mathrm{SiO}_{2}\right)$ (average particle size of $63 \mu \mathrm{m}$, Kojundo Chemical Lab. Co., Ltd., Japan) mixed with 2 moles of black carbon (average particle size of $20 \mu \mathrm{m}$, Kojundo Chemical Lab. Co., Ltd., Japan), using a mortar and pestle.

Then, we made the pellets with different sizes from the mixed powders and dried them at $80{ }^{\circ} \mathrm{C}$ for 90 minutes in a pan. We compared two different binder agents: water and polyvinyl alcohol (PVA) $\left[-\mathrm{CH}_{2} \mathrm{CHOH}-\right]_{n}$ (Aldrich Chemical Company, USA), as shown in Table 2.

An alumina crucible was used to preserve the prepared pellets, as microwave irradiation does not affect this material which is considered as transparent. The intensity of microwave radiation depends on the design and geometry of the furnace chamber, thus, the crucible must be placed inside the chamber at the point of high concentration of microwave irradiation [15]. Moreover, to avoid energy loss, we used an insulating alumina fiber blanket to cover the crucible. The experiments were carried in an inert atmosphere of Ar gas under a pressure of $\sim 10^{5} \mathrm{~Pa}$.

During the experiment, an infrared thermometer, with a temperature range of $400{ }^{\circ} \mathrm{C}$ to $2500{ }^{\circ} \mathrm{C}$, was used to measure the temperature on the crucible side. Unfortunately, we were unable to use a thermocouple to measure temperature because it causes damages to samples when they are exposed to microwave irradiation [15].

Instead, simulations of the electromagnetic field distribution with the temperature profile can be used to predict the temperature of the mixture inside the crucible during microwave heating of the carbothermic reduction of $[16,17]$.

\section{Results and discussion}

The samples after reactions are presented in Fig. 2. Sample a reacted completely at $1496{ }^{\circ} \mathrm{C}$, however, sample b reacted partially $(65 \%)$ at $1361{ }^{\circ} \mathrm{C}$. Sample c remained unreacted 
Table 2. Raw materials for pellets preparation

\begin{tabular}{ccccc}
\hline Sample & Mixture $[\mathrm{g}] \mathrm{SiO}_{2}-\mathrm{C}$ & Binder agent & Pellets size [mm] & $\begin{array}{c}\text { Ratio of binder by } \\
\text { weight [\%] }\end{array}$ \\
\hline \hline (a) & 200 & water & 5 & 10 \\
(b) & 200 & water & 7 & 10 \\
(c) & 200 & water & 10 & 10 \\
(d) & 200 & PVA & 5 & 3 \\
\hline
\end{tabular}

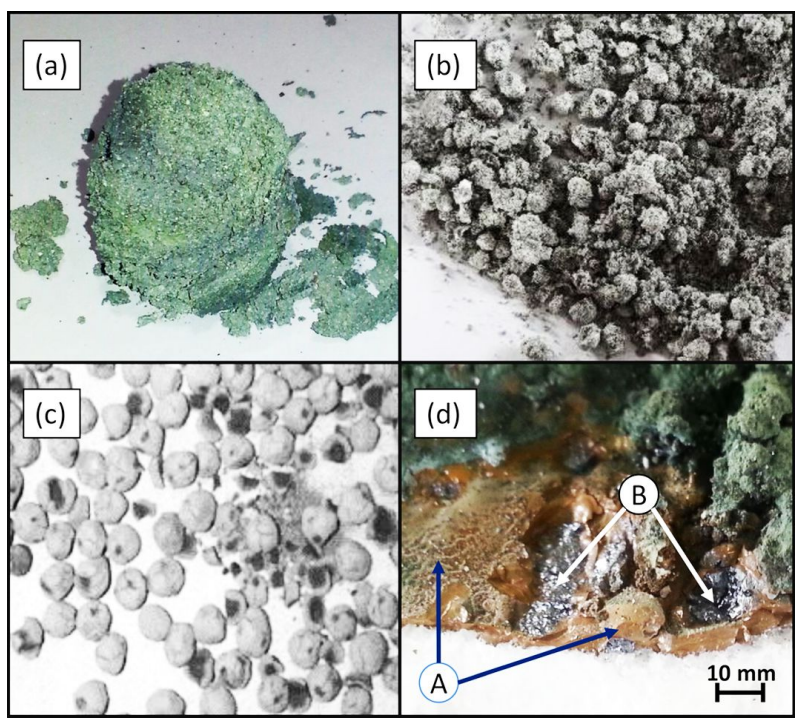

Fig. 2. Formation of silicon carbide in sample a, partial reaction in sample $b$, non-reacted pellets in sample $\mathrm{c}$ and formation of silicon phases in sample d.

at a temperature of $1252{ }^{\circ} \mathrm{C}$. The change of the reactions percentages was due to the effect of pellet size and the microwave energy absorption. In sample $\mathrm{d}$, the temperature increased to about $1678{ }^{\circ} \mathrm{C}$. As shown in Fig. 2d, there are many colors: brown, grey metallic and green. The green color corresponds to silicon carbide, brown and metallic grey correspond to different phases of silicon according to the manufacturing conditions [18]. The weight loss of the samples a, b, c and d was $85 \mathrm{~g}, 35 \mathrm{~g}$, $9 \mathrm{~g}$, and $150 \mathrm{~g}$, respectively. In general, weight loss was caused by the generation of $\mathrm{CO}, \mathrm{CO}_{2}$ and $\mathrm{SiO}$ gases [3].

\subsection{Raman analysis}

Raman spectrometer used in our research was (NRS-3300, Jasco, USA). Fig. 3 shows the Raman scattering spectra of sample $a$, sample $b$ and sample d. In sample a, we notice the presence of peaks at $\sim 523 \mathrm{~cm}^{-1}$ which can be attributed to $\mathrm{Si}$, and $\sim 794 \mathrm{~cm}^{-1}$ referred to the transverse optical (TO) mode of SiC which consists mainly of a cubic polytype structure $[19,20]$. In sample $b$, the observed peaks correspond to the TO phonon mode at $\sim 789 \mathrm{~cm}^{-1}$, and low intensity longitudinal optical (LO) phonon mode at $\sim 973 \mathrm{~cm}^{-1}$, attributed to $\mathrm{SiC}[19,21]$.

Moreover, as shown in Fig. 2d, the dominant peak observed is located at $\sim 515 \mathrm{~cm}^{-1}$ in position A which corresponds to brown colour silicon, and another peak observed at $\sim 517 \mathrm{~cm}^{-1}$ in position $\mathrm{B}$ can be attributed to metallic and greyish silicon [22]. These different colors of silicon correspond to the two allotropes of silicon, i.e., crystalline and amorphous silicon.

\section{Conclusions}

In conclusion, following our experiments we succeeded to produce silicon by a microwaveheating process using a mixture of silica and carbon. It is important to note that many parameters influence the chemical reaction process such as pellet size, binding agent and reaction temperature. Polyvinyl alcohol as a binder agent improved heat transfer and resulted in a $17 \%$ efficiency in silicon production.

On the basis of the promising findings presented in this paper, work on the remaining issues 


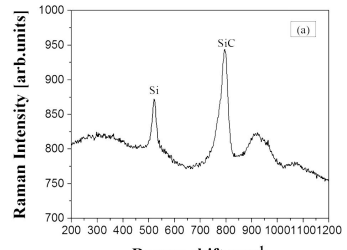

Raman shift $\left|\mathrm{cm}^{-1}\right|$
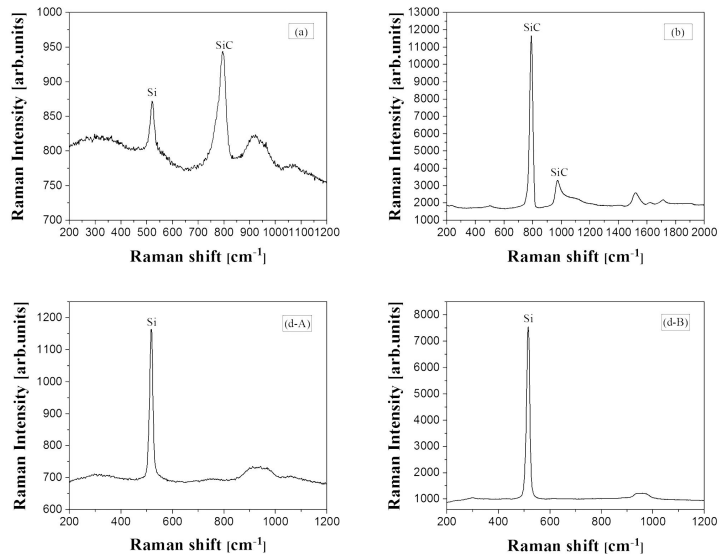

Raman shift $\left[\mathrm{cm}^{-1}\right.$

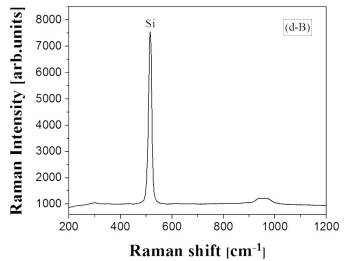

Fig. 3. Raman scattering spectra of samples $a, b$ and $d$. (a) peak at $523 \mathrm{~cm}^{-1}$ corresponds to silicon and peak at $794 \mathrm{~cm}^{-1}$ corresponds to silicon carbide, (b) peaks at $789 \mathrm{~cm}^{-1}$ and at $973 \mathrm{~cm}^{-1}$ correspond to silicon carbide, (d-A) peak at $515 \mathrm{~cm}^{-1}$ corresponds to silicon, (d-B) peak at $517 \mathrm{~cm}^{-1}$ corresponds to silicon

is continuing and will be presented in future papers. Therefore, we intend to make a new crucible design to prevent silicon monoxide $(\mathrm{SiO})$ gas loss during the carbothermic reduction, and to achieve continuous production of solar grade silicon under microwave irradiation.

\section{Acknowledgements}

We gratefully acknowledge the support from the JSTJICA, Seavac Densetsu Kyogo Co., Ltd., and we would like to thank JPM Silicon GmbH for help with their know-how of the microwave process.

\section{References}

[1] Boucetta A., Benioub R., Chahtou A., HedDadu S.M., Ogasawara T., Furuya Y., ITAKa K., Mater. Trans., 57 (2016), 1936.

[2] Filsinger D.H., Bourrie D.B., J. Am. Ceram. Soc., 73 (1990), 1726.

[3] Benioub R., Boucetta A., Chahtou A., HedDadj S.M., Adnane M., Furuya Y., ITAKa K., Mater Trans., 57 (2016), 1930.

[4] Thostenson E.T., Chou T.W., Compos. Part A-Appl. S., 30 (1999), 1055.

[5] Ma S.J., Zhou X.W., Su X.J., Mo W., Yang J.L., LIU P., Miner. Eng., 22 (2009), 1154.
[6] Sun J., Wang W., Yue Q., Materials, 9 (2016), 231.

[7] Grant E., Halstead B. J., Chem. Soc. Rev., 27 (1998), 213.

[8] Cetiner S., Sirin S., Olariu M., Sarac A. S., Adv. Polym. Tech., 35 (2016).

[9] Metaxas A.C., Meredith R.J., Industrial Microwave Heating, Peter Peregrinus Ltd., London, 1983.

[10] Horikoshi S., Schiffmann R.F., Fukushima J., SERPONE N., Materials Processing by Microwave Heating, in: Microwave Chemical and Materials Processing, Singapore, 2018, p. 321.

[11] Elektromagnatik S.B.P.G., Malays. J. Analy. Sci., 20 (2016), 444.

[12] Clark D.E., Folz D.C., West J.K., Mater. Sci. Eng. A-Struct., 287 (2000), 153.

[13] Kim T., LeE J., LEE K.H., Carbon Lett., 15 (2014) 15.

[14] BArba A.A., Amore M., Relevance of dielectric properties in microwave assisted processes, in: Costanzo S. (Ed.), Microwave Materials Characterization, InTech, London, 2012, p. 91.

[15] RezaiI N., MaI J.P., Multiphysics Modelling of a Microwave Furnace for Efficient Silicon Production, COMSOL, Munich, 2016.

[16] Pielsticker S., Simulationen zum Temperaturprofil im Reaktionsgemisch der carbothermischen Reduktion von Quarz im Mikrowellenofen, JPM Silicon GmbH, Germany, 2014.

[17] Santos T., Valente M.A., Monteiro J., Sousa J., Costa L.C., Appl. Therm. Eng., 31 (2011), 3255.

[18] Benioub R., Adnane M., Boucetta A., Chahtou A., Kobatake H., Furuya Y., Itaka K., $J$. New. Tech. Mater., 7 (2017), 90.

[19] Roma G., Phys. Status. Solidi A, 213 (2016), 2995.

[20] Barbouche M., Zaghouani R.B., Benammar N.E., Khirouni K., Ezzaouia H., Int. J. Adv. Manuf. Tech., 91 (2017), 1339.

[21] Wasyluk J., Perova T.S., Kukushin S A., OsIPOV A.V., FEOKTISTOV N.A., GRUdinkin S.A., Raman investigation of different polytypes in $\mathrm{SiC}$ thin films grown by solid-gas phase epitaxy on $\mathrm{Si}$ (111) and $6 \mathrm{H}$ SiC substrates, in: Materials Science Forum, Trans Tech Publications, Switzerland, 2010, p. 359.

[22] Deschaines T., Hodkiewicz J., Henson P., in: Thermo Fisher Scientific, Madison, WI, USA, 2009.

Received 2018-06-23 Accepted 2019-01-05 